Research Article

\title{
Gall bladder perforation - is it still a diagnostic dilemma: a retrospective study
}

\section{Venkat Narsimha Reddy Nandyala*, Praveen pallam, Santosh babu Chintakindi, Likiteshwar Pallagani, Gopikanth Kundarapu}

Department of General Surgery, Gandhi Medical College, Musheerabad, Telangana, Secunderabad

Received: 28 December 2015

Revised: 21 February 2016

Accepted: 29 February 2016

\author{
*Correspondence: \\ Dr. Venkat Narsimha Reddy Nandyala, \\ E-mail: nvn.reddy@yahoo.com
}

Copyright: ( ) the author(s), publisher and licensee Medip Academy. This is an open-access article distributed under the terms of the Creative Commons Attribution Non-Commercial License, which permits unrestricted non-commercial use, distribution, and reproduction in any medium, provided the original work is properly cited.

\begin{abstract}
Background: Gall bladder perforation though an unusual complication following acute cholecystitis is no longer a cause for diagnostic dilemma among patients presenting with signs and symptoms of peritonitis. This would be possible following a detailed history and a systematic clinical examination of the patients presenting with acute abdomen secondary to gall bladder perforation and confirmation by a readily available diagnostic modality like ultrasound abdomen.

Methods: A total of 18 patients who presented with signs and symptoms of peritonitis following gall bladder perforation over a period of two years were studied retrospectively.A detailed history elicited from these patients and a meticulous clinical examination carried out followed by an ultrasound abdomen facilitated an early diagnosis and immediate surgical intervention thereby ensuring a better outcome. Factors which led to gall bladder perforation secondary to acute cholecytsitis were also looked into.

Results: 17 patients were preoperatively diagnosed to have gall bladder perforation. 83\%of the patients had calculus cholecystitis. Diabetics constituted the majority of the cases (15). 15 out of 18 (83\%) patients had type 1 perforation whereas the other 3 had type 2 perforation. 11 patients had undergone subtotal cholecystectomy, 4 cholecystectomy and only 3 patients had cholecystectomy. Infective complication rate was high but only 1 patient had died postoperatively.

Conclusions: A relevant history and a systematic clinical examination along with diagnostic imaging (USG and CT abdomen) would be significant in establishing an early diagnosis of gallbladder perforation. Morbidity and Mortality were high among patients presenting with gall bladder perforation secondary to a calculus cholecystitis.
\end{abstract}

Keywords: Gall stones, Cholecytitis, Peritonitis

\section{INTRODUCTION}

Gall Bladder Perforation though an uncommon complication following acute cholecystitis, often remained a cause for diagnostic dilemma among surgeons while managing patients presenting with clinical signs and symptoms of peritonitis. This would often delay the diagnosis and result in morbidity and mortality with a significant impact on the outcomes. Gallbladder perforation is almost an exclusive complication of acute cholecystitis. $^{1-6}$

In majority of the patients with acute calculus cholecystitis impacted stone in the cystic duct slips back in the gallbladder and enables the cholecystitis to resolve. If cholecystitis does not resolve due to persistent impaction of stone, inflammation may progress, an empyema may develop. Persistent inflammation and 
gallbladder distension due to impacted stone leads to ischemia, necrosis, and perforation. Perforation at fundus is less likely to be covered by omentum, so gall stones and bile are more likely drain into peritoneal space causing diffuse peritonitis. If the perforation occurs at the neck or the duct, it is more easily sealed off by the omentum or the intestines and the condition remains limited to the right upper quadrant with formation of local inflammation and pericholecystic fluid. ${ }^{6-9}$

Neimeier classified gall bladder perforation in three categories. $^{2-8}$

- Type-1 (acute): free perforation with generalized peritonitis.

- $\quad$ Type 2 (sub-acute): localized peritonitis.

- Type 3 (chronic): cholecystoenteric fistula of the gall bladder with or without cholelithiasis.

The incidence of gallbladder perforation in acute cholecystitis has been reported to range from 2 to $18 \%$ and in between calculus and acalculous cholecystitis, the overall incidence of gallbladder perforation due to acalculous cholecystitis is higher, reaching approximately 10 to $20 \%$. $^{9,10}$

The mortality reported among the patients with gall bladder perforation secondary to acalculus cholecystitis is much higher when compared to calculus cholecystitis. This is because of severe infection due to the predisposing factors accounting for high prevalence of acalculus cholecystitis among the patients admitted to Intensive care units. Non obstructive cholecystitis with intense inflammation with virulent infection and existence of immuno-compromised state leads to thrombosis of blood vessels and trans luminal necrosis and perforation. ${ }^{11,12}$

Clinically patients with gallbladder perforation presenting with diffuse peritonitis may not always give symptoms related to biliary colic in the past there by making us suspect hollow viscous perforation which is most often the likely cause. This often leads to a difficulty in arriving at a definitive diagnosis clinically and it remains a diagnosis by exclusion after a pneumoperitoneum due to hollow viscous perforation is ruled out on a plain $\mathrm{X}$ ray erect abdomen. Clinical signs and symptoms of subacute gall bladder perforation with pericholecystic fluid collection mimic acute cholecystitis and patients are likely to be managed conservatively in the initial phase. Chronic gall bladder perforation with cholecysteneteric fistula often remains asymptomatic until the patients develop clinical features of intestinal obstruction due to gall stone ileus. ${ }^{13}$

Also, the sonographic appearances of gall-bladder perforation are diverse and nonspecific which include wall thickening $(>3 \mathrm{~mm})$, distension (largest diameter
>3.5-4.0 cm), gall-stones, coarse intracholecystic echogenic debris and bile duct dilatation, but most often it is the experience of the sonologist which helps in diagnosing a gall bladder perforation. Limitations of ultrasound like demonstrating a gall bladder perforation in the presence of increased intestinal gas and pain can be overcome by CT Abdomen. Though CT scan of the abdomen a sensitive tool in establishing the diagnosis of gall bladder perforation would not be possible always in an emergency set up. ${ }^{13}$

All these factors often cause an undue delay in the diagnosis there by having a significant impact on the outcomes. This retrospective study focuses on the factors which can predict gall bladder perforation in patients presenting with peritonitis based on history and clinical examination supported by basic investigations like X-ray and ultrasound abdomen. This would aid in an early diagnosis and an immediate surgical intervention, the key determinants in improving the outcomes.

The objective of these studies was to study the role of clinical evaluation and imaging in predicting gall bladder perforation among patients presenting with peritonitis. $\mathrm{T}$

he primary objective of these studies was to study the importance of systematic clinical evaluation supported by basic diagnostic imaging in establishing a preoperative diagnosis of gall bladder perforation and to evaluate the outcomes of surgery among patients presenting with gall bladder perforation following an early detection and an emergency surgical intervention.

The secondary objective of these studies was to predict the risk factors for gall bladder perforation among patients presenting with signs and symptoms of acute cholecystitis.

\section{METHODS}

A retrospective observational study was carried out during period of October 2013 to October 2015.

\section{Study population}

Patients of both genders who belonged to the age group of 18 to 60 years and who underwent emergency laparotomy and procedure for a gallbladder perforation either diagnosed preoperatively or intraoperatively were included.

Data related to 18 patients who underwent emergency laparotomy for gall bladder perforation over a period of two years was collected and analyzed. Epidemiological factors, duration of complaints, previous episodes of acute (calculus/acalculus) cholecystitis, clinical signs and symptoms at the time of presentation and the diagnosis whether made preoperatively or intraoperatively and the outcomes following emergency surgery were looked into. 
RESULTS

Table 1: Age group.

\begin{tabular}{|ll|}
\hline Age group & Number of patients \\
\hline $18-28$ & 0 \\
\hline $28-38$ & 2 \\
\hline $38-48$ & 7 \\
\hline $48-60$ & 9 \\
\hline
\end{tabular}

Table 2: Gender.

\begin{tabular}{|ll|}
\hline Male & Females \\
\hline 11 & 7 \\
\hline
\end{tabular}

Table 3: Previous H/o recurrent attacks of biliary colic.

\begin{tabular}{|ll|}
\hline Positive & Negative \\
\hline 7 & 11 \\
\hline
\end{tabular}

Table 4: Duration of symptoms of the present episode.

\begin{tabular}{|llll|}
\hline$<24$ hours & $\mathbf{2 4 - 4 8}$ hours & $\mathbf{4 8 - 7 2}$ hours & $\begin{array}{l}\text { Beyond } 72 \\
\text { hours }\end{array}$ \\
\hline 3 & 5 & 7 & 3 \\
\hline
\end{tabular}

Table 5: Jaundice.

\begin{tabular}{|ll|}
\hline Present & Absent \\
\hline 7 & 11 \\
\hline
\end{tabular}

Table 6: Diabetes.

\begin{tabular}{|ll|}
\hline Present & Absent \\
\hline 15 & 3 \\
\hline
\end{tabular}

Table 7: Diagnosis.

\begin{tabular}{|ll|}
\hline Preoperative & Intraoperative \\
\hline 17 & 1 \\
\hline
\end{tabular}

Table 8: Intraoperative findings of patients.

\begin{tabular}{|lc|}
\hline Intraoperative Findings & Number of patients \\
\hline Empyema gall bladder & 15 \\
\hline Cholelithiasis & 15 \\
\hline Choledocholithiaisis & 3 \\
\hline
\end{tabular}

\section{Intraoperative findings}

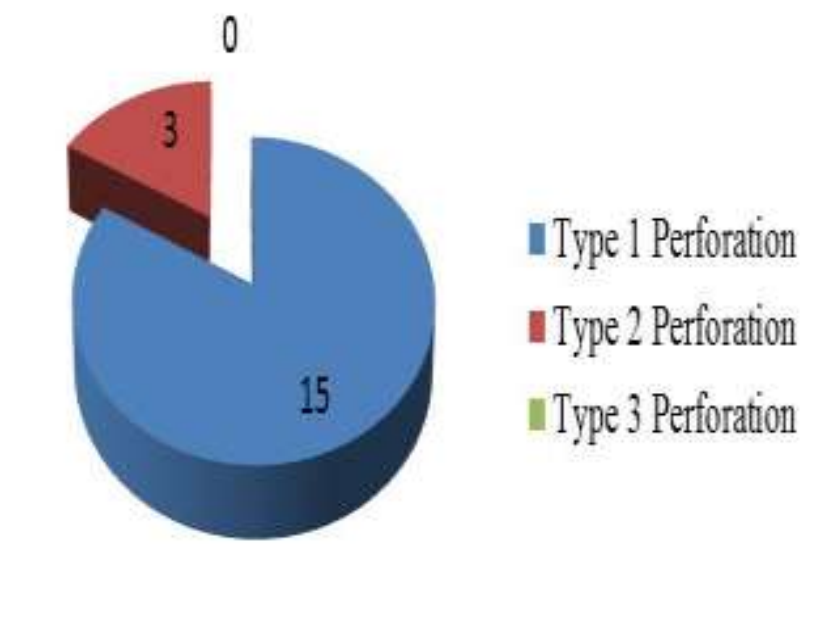

Figure 1: Type of perforation.

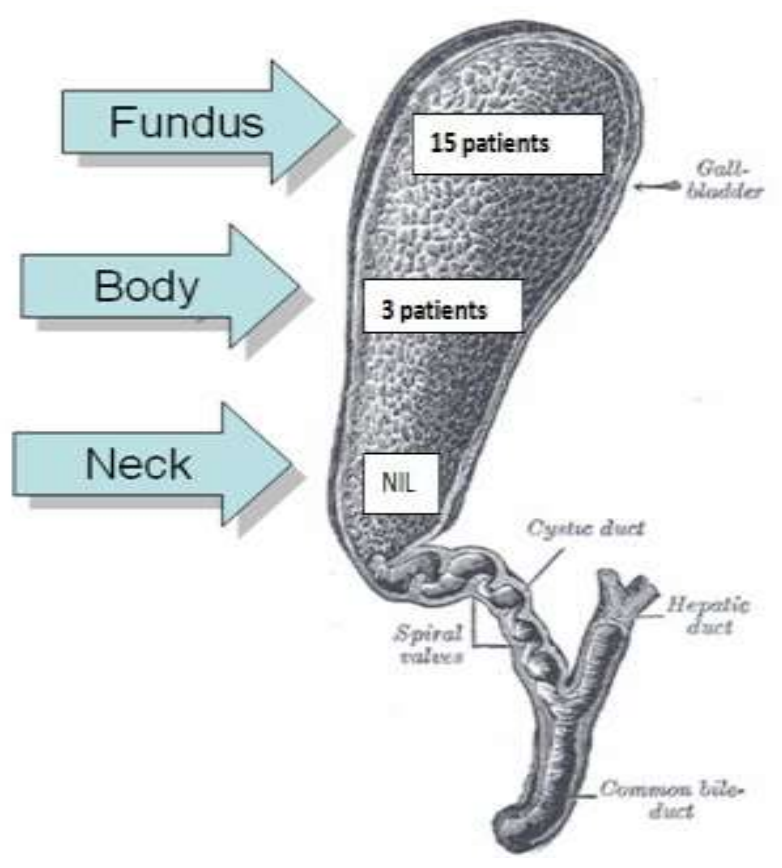

Figure 2: Sites of gall bladder perforation.

Table 9: Postoperative complications-morbidity and mortality.

\begin{tabular}{|llllll|}
\hline Complications & $\begin{array}{l}\text { Surgical Site } \\
\text { Infections }\end{array}$ & $\begin{array}{l}\text { Respiratory tract } \\
\text { infection }\end{array}$ & $\begin{array}{l}\text { Urinary tract } \\
\text { infection }\end{array}$ & $\begin{array}{l}\text { Mean } \\
\text { hospital }\end{array}$ & Mortality \\
\hline Calculus Cholecystitis & 11 & 7 & 3 & 8 days & Nil \\
\hline Acalculus Cholecystitis & 3 & 3 & 2 & 15 days & 1 \\
\hline
\end{tabular}




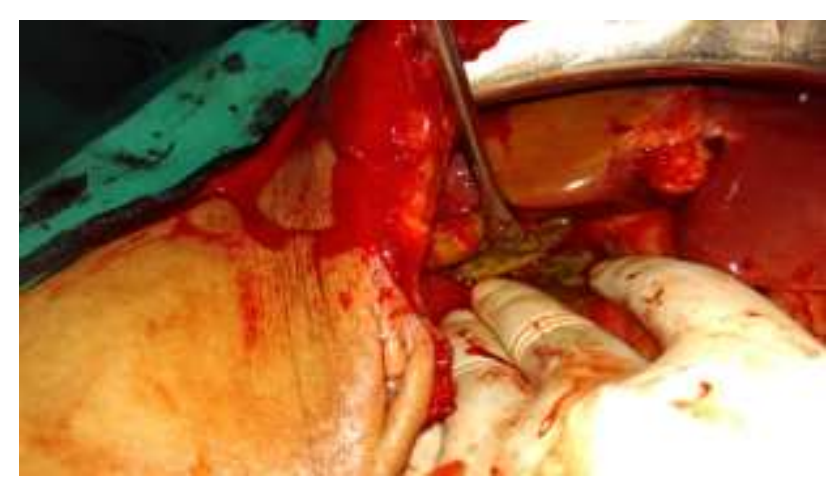

Figure 3: Gall bladder perforation intraoperative.

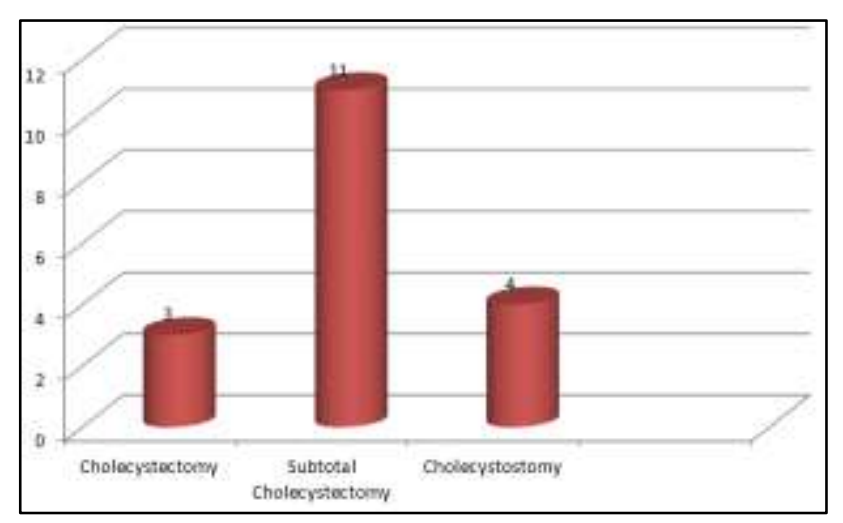

Figure 4: Procedure done.

\section{DISCUSSION}

Gall Bladder perforation is a rare surgical complication following acute cholecystitis among patients presenting with peritonitis as reported among 18 patients over a period of 2 years.

The commonest age group where gall bladder perforation was reported is 48 to 60 years. Out of 9 patients from this group 8 were males and one female. There were 7 patients who presented with gall bladder perforation in the age group 38-48 years and five of them were females which corroborates with high incidence of gall stone disease among fatty, forty, fertile females.

The youngest patient who had reported with gall bladder perforation was a male, 36 years old and the oldest patient was also a male 61years old and both of them were diabetics on treatment.

A detailed probing into the history is mandatory as 7 out of 18 patients gave symptoms related to previous episodes of biliary colic which can make us suspect a possibility of gall bladder perforation, this emphasises the need for eliciting relevant history in arriving at a correct diagnosis.

Type I was the commonest type of perforation with signs of diffuse peritonitis was seen among fifteen patients.
This data coincides with other studies where Type I perforation was commonly reported.

Diabetes leading to empyema of the gall bladder following acute calculus cholecystitis is most often the risk factor for gall bladder perforation as reported among 15 patients.

Jaundice was reported among only 3 patients presenting with gall bladder perforation secondary to stones in the common bile duct whereas there was no icterus clinically documented among the patients presenting with suspected gall bladder perforation.

Jaundice remains as an unreliable clinical sign in diagnosing gall bladder perforation secondary to gall stone induced cholecystitis unless associated with stones in the common bile duct.

Eliciting relevant history and a meticulous clinical examination with the support of basic imaging like plain $\mathrm{X}$-ray abdomen erect, ruling out pneumoperitoneum and an ultra sound abdomen with suspected disruption of the gall bladder wall enabled us to make a probable diagnosis of gall bladder perforation preoperatively among ten patients. CT scan abdomen done for 8 patients with equivocal findings on ultrasound abdomen revealed gall bladder perforation among 7 patients and in one patient it could be made out only intraoperatively. This highlights the importance of clinical evaluation and basic imaging modalities in arriving at a diagnosis of gall bladder perforation. CT scan would be an ideal choice only in those patients with equivocal findings both on clinical examination and ultrasound abdomen.

Thirteen patients had type I perforations involving the fundus of the gall bladder as it is the least vascularised portion of the gall bladder which can give way easily in the presence of empyema secondary to gall stone.

Three patients who had presented early with gall bladder perforation and those who have been diagnosed early after a delayed presentation within 48 hours with an early surgical intervention had better outcomes Ten patients presented beyond 48 hours with signs and symptoms of diffuse peritonitis and three of them with a delayed presentation after 72 hours had a prolonged mean hospital stay secondary to delayed recovery.

Three patients had type II perforation two involving the fundus and one involving the body with localised signs of peritonitis confined to the right hypochondria.

After exploratory laparotomy a complete cholecystectomy was possible only among three patients presenting with gall bladder perforation whereas subtotal cholecystectomy was performed in 11 patients due to dense adhesions in the calots triangle. Cholecystectomy using a malecots catheter was done in four patients in 
view of inflammatory phlegmon followed by an elective Cholecystectomy six weeks later in 3 patients.

Surgical site infections were more common among patients with delayed presentation beyond 48 hours due to grossly contaminated surgical wound.

The incidence of respiratory and urinary tract Infections were also high among this group with a late presentation there by prolonging the hospital stay by a week.

Morbidity and Mortality reported among patients presenting with gall bladder perforation secondary to acalculus cholecystitis was very high. This is in view of severe sepsis for which these patients were admitted to the intensive care units accounting for high incidence of acalculus cholecystitis and subsequent perforation.

\section{CONCLUSION}

A relevant history and a systematic clinical examination would be significant in establishing an early diagnosis of gallbladder perforation among patients presenting with signs and symptoms of peritonitis supported by X-ray and ultrasound abdomen. CT scan abdomen would be an ideal choice only among patients presenting with equivocal findings.

Morbidity and mortality reported were high among patients presenting with gall bladder perforation secondary to acalculus cholecystitis.

Morbidity related to gallbladder perforation secondary to calculus cholecystitis was seen more often among patients who had delayed presentation.

Gallbladder perforation should be suspected among elderly males with history of gall stone disease associated with diabetes and empyema of gallbladder presenting with clinical signs and symptoms of acute calculus cholecystitis where the symptoms failed to resolve after conservative treatment beyond 72 hours and where in repeated clinical and serial ultrasound abdomen evaluations help in establishing an early diagnosis of gall bladder perforation to facilitate better outcomes.

Funding: No funding sources Conflict of interest: None declared Ethical approval: Not Required

\section{REFERENCES}

1. Roslyn JJ, Bussutil RW. Perforation of gall bladder a frequently mismanaged condition. Am J Surg. 1979;137(3):307;12.

2. Green LF. Peroration of gall bladder. JR Coll Surg Edin.1983;28;169-73.

3. Roslyn JJ, Thompson JE, Darwin H, Denbesten L The American Journal of Gastroenterology. 1987;82(7):636-40.

4. Ong CL, Wong HT, Rauff A. Acute gall bladder perforation- a dilemma in early diagnosis. Gut.1991;32:956-8.

5. Wang AJ, Wnad TE, Lin CC, Lin SC, Shih SC. Clinical Predictors of severe gall bladder complications in acute acalculus cholecystitis. World J Gastroenterol. 2003;9:2821-3.

6. Kim HJ, Park SJ, Lee SB, Lee JK, Jung HS, Choi CK, et al. A Case of Spontaneous Gallbladder Perforation. Korean J Intern Med. 2004;19(2):12831.

7. Derici H, Kara C, Bozdad AD, Nazli O, Tansug T, Akca E . Diagnosis and treatment of gall bladder perforation World J Gastrenterol. 2006;12:7832-6.

8. Alvi AR, Ajmal, Saleem T. Acute free perforation of gall bladder encountered at initial presentation in a 51 years old man: a case report cases J. 2009;2(1):1666.

9. Khan SA, gulfam AW, Arshad Z, Hammed K, Shoib M. Gall bladder perforation a rare complication of acute cholecystitis. J Pak Med. Assoc. 2010;60:228-9.

10. Pandove PK, Dhuris S, Kumar A, Sharda VK. Spontaneus multiple gall bladder perforations in a patient of hepatitis C: a Case Report. JIMSA. 2014;27(1):28.

11. Vipul D, Yagnik S. Type-1 gall bladder perforation: Rare Complication of Cholelithiasis. J Gastroenterol. 2011;17(1):84.

12. Ravindra S, DateSri G, Thrumurthy S, Mohammed A, UmerKishore G, Pursnani et al. Gallbladder perforation: Case series and systematic review. 2012;10(2):63-8.

13. Beauchamp, Evers, Mattox. Sabiston Textbook of Surgery. The Biological basis of Modern Surgical Practice. $19^{\text {th }}$ edition. Philadelphia; 2012:1515-1547.

Cite this article as: Nandyala VNR, Pallam P, Chintakindi SB, Pallagani L, Kundarapu G. Gall bladder perforation - is it still a diagnostic dilemma: a retrospective study. Int Surg J 2016;3:609-13. 